\title{
Ultradian Components of Human Sleep/Wake Patterns During Disentrainment
}

S.S. Campbell ${ }^{1}$ and J.Zulley ${ }^{2}$

${ }^{1}$ Department of Psychiatry, University of California, San Diego, CA 92161, USA

${ }^{2}$ Max-Planck-Institut für Psychiatrie, Kraepelinstrasse 10, 8000 München 40, FRG

"Napping got a bad reputation somewhere
along the line and I resent it."
Andy Rooney

INTRODUCTION

The likelihood that napping behavior in adult humans is the expression of a part of the endogenous sleep/wake system has been recognized by numerous authors (BENOIT 1984; BROUGHTON 1975; CAMPBELL 1984; DINGES et al. 1983; KLEITMAN 1963; LAVIE and SCHERSON 1981; NAKAGAWA 1980; TUNE 1968, 1969; WEBB 1978; ZULLEY and CAMPBELL 1985a,b). Until relatively recently, experimental data regarding spontaneous napping have been lasking and it has been necessary, therefore, to rely largely on subjective reports and anecdotal evidence to support such a proposal. For example, both college students (WHITE 1974; WEBB and DUBE 1981) and individuals of retirement age (TUNE 1968) have reported increased frequencies of daytime sleep in response to their less-structured lifestyles. Similarly, the prevalence of siesta cultures has often been cited as an indication that there exists a natural tendency for a period of rest approximately halfway through the major waking interval.

These special cases notwithstanding, the usual view of human sleep/ wake organization is that of a monophasic pattern, characterized by a major waking episode of about $16 \mathrm{~h}$ duration followed by a major sleep episode of about $8 \mathrm{~h}$ duration. The ubiquity with which this monophasic organization of sleep and wakefulness occurs may explain, in part, the general paucity of experimental data specifically addressing noncircadian components of the sleep/wake system, i.e., spontaneous napping, in humans. 

Moreover, as has been noted by WEBB (1978), the very nature of naps (i.e., usually brief interruptions of relatively long waking intervals) makes them "uncontrollable and interfering sources of experimental variance" (p. 316) in most studies which are usually focused on major components of sleep, waking, and performance. Because of this focus, napping behavior is typically suppressed, either by specific experimental instructions or as a consequence of continuous performance, psychological or other testing.

Yet the available experimental evidence suggests that while naps may, indeed, interfere in the analyses of circadian components of sleep and wakefulness, the reverse may also be true. That is, by imposing a monophasic, circadian sleep regimen on subjects by circumscribed experimental protocols, the expression of putative noncircadian components of the sleep/wake system may be effectively masked. It has been shown, for example, that simply by removing restrictions on sleep in an otherwise typical time-free environment, the frequency of occurrence of sleep episodes, and the variability in the duration of episodes, increases substantially (WEBB and AGNEW 1974). In this sense, then, experimental instructions or behavioral demands which restrict the spontaneous initiation of sleep across the nychthemeron may be viewed as interfering sources of experimental variance in the examination of putative noncircadian components of adult human sleep.

Behavioral demands which may interfere with the expression of sleep tendency need not necessarily be imposed by experimental instructions, social/occupational pressures, or other external sources. Such controls may be self-imposed as well. It is not uncommon to delay, displace, or even omit typically scheduled sleep episodes in favor of self-imposed alternatives to sleep, such as finishing a good book, attending a social function, or completing an important project. It is, likewise, not unusual to attempt to overcome a period of drowsiness by a transient increase in physical activity, or, for example, by drinking a cup of coffee or tea.

Thus it is clear that the sleep behavior exhibited by a human adult may be influenced to a substantial degree by at least two environmental factors in addition to the biological system mediating the sleep response: external and self-imposed behavioral controls.

Because external and self-imposed behavioral controls may exert strong mediatory influences on the physiological sleep/wake system, it should 
be apparent that the behavioral manifestation of sleep and wakefulness observed in daily life, and in many experimental conditions, does not necessarily reflect underlying physiological sleep tendency. By way of analogy, the course of a river, after imposition of restraints and controls in the form of dams and levees, in an effort to structure the river for more efficient use, probably does not reflect accurately the natural dynamics of the river.

There is growing evidence that this is also the case with regard to human sleep. Thus, one approach to more closely examine properties of putative ultradian components of the human sleep/wake system would be to provide conditions under which the system was permitted to follow a course of least resistance. This would include not only the elimination of experimental instructions relative to when and when not to sleep, but also would require minimization of behavioral alternatives which may be incompatible with the sleep response.

In the following study, we have employed a "disentrained" environment in an effort to invoke such conditions. It was reasoned that, in response to the lack of behavioral options in such an environment, subjects would be more likely to respond to periods of drowsiness, not by attempting to overcome such a state, but rather by unambiguously expressing sleep tendency in the form of napping. In turn, it was hypothesized that the view of sleep and wakefulness which emerged from such an environment may provide a more accurate reflection of the biological mechanisms underlying the human sleep/wake system.

METHOD

Subjects

Nine paid subjects (4 females, 5 males) aged 19-37 years (mean age, 25.1 years) participated in the study. Subjects were selected who reported normal sleep patterns and the absence of both chronic health problems and acute illness. No subject reported habitual napping, though most subjects reported napping occasionally. Prior to participation, each subject was informed, in detail, of the environmental conditions to be used in the study and each was informed of the general aim of the study. 
Disentrainment

The term "disentrainment" was selected to distinguish the current conditions from those typically employed in time-free environments, in which time cues are removed but other aspects of the environment remain essentially the same as in daily life, i.e., subjects are asked to continue daily activities and are usually requested to "structure" their days. "Disentrainment" was initially used in a previous paper (CAMPBELL 1984) to describe an environment which included enforced bed rest. In the present study, the same behavioral conditions were imposed, with the exception of enforced bed rest.

During the period of disentrainment subjects were confined individually in underground apartments shielded from all natural and artificial time cues. Subjects were allowed to move freely about the isolation unit, but were requested not to engage in strenuous exercise. Subjects were, in addition, prohibited from reading, writing, listening to music, and so on. They were specifically instructed not to structure their days, but rather to eat and sleep when inclined to do so. Food and noncaffeinated beverages, as well as kitchen facilities, were available in the isolation unit. Illumination was provided by fluorescent lighting in the ceiling and by several incandescent lamps on tables and over the bed. Control of light and darkness was at the discretion of each subject.

In summary, the physical environment used here was essentially the same as environments employed in standard human circadian research (cf. WEVER 1979). The difference was that there were no constraints placed on the initiation of sleep and behavioral options to sleep were extremely limited.

\section{Procedure}

Each subject slept for one night in the isolation unit immediately prior to the 72-h disentrainment period. Subjects were permitted to self-select bedtime on this occasion, as well as on all occasions during disentrainment. At 0800 on the morning following the baseline night, each subject was signalled that the experimental period had begun. They were instructed to acknowledge having heard the signal, but they were not required to get out of bed (i.e., they could return to sleep if so inclined). 
During the entire period, including baseline night, the EEG, EOG, and EMG of each subject was continuously monitored via a Glonner Biomes 80 telemetry system. The signals were fed through a standard Siemens physiograph for output to paper. All records were subsequently scored in 30-s epochs following standard scoring procedures (RECHTSCHAFFEN and KALES 1968). Sleep onset was defined by the first epoch containing a sleep spindle or K-complex.

While awake, subjects wore the telemetry transmitter on a belt around the waist. During sleep episodes, the transmitter could be placed on a table beside the bed. Because of the relatively extended recording interval, the transmitter was powered by a 12-volt auto battery, connected by a cable approximately $6 \mathrm{~m}$ in length. Thus, it was unnecessary to change batteries during the disentrainment period.

Temperature was recorded each minute via a rectal probe, also connected by a $6 \mathrm{~m}$ long cable. Cables were of sufficient length to allow subjects complete freedom of movement around the isolation unit.

Communication with subjects was possible through an intercom system, but this was used only to request subjects to reattach electrodes when a loss of signals warranted such requests. While transmission and recording difficulties were, in most cases, corrected by the subjects, it was necessary on several occasions to enter the isolation unit to reattach electrodes or make mechanical adjustments. Such interruptions, as well as requests to subjects to attend to equipment failures, were made only during ongoing waking episodes.

\section{RESULTS}

While there were a limited number of sleep episodes with durations of less than $30 \mathrm{~min}(13.6 \%$ of total, $N=9)$, these sleep episodes (mean duration, $10.2 \mathrm{~min}$ ) accounted for less than one percent of total sleep obtained. In the following analyses, therefore, a sleep episode is considered as such when sleep continued for at least $30 \mathrm{~min}$. Similarly, there were a limited number of waking periods which continued for over $15 \mathrm{~min}$ but for less than $60 \mathrm{~min}(16.2 \%$ of total, $N=12)$. However, the large majority of waking episodes were of greater than $1-h$ duration. Furthermore, examination of sleep episodes, particularly major nocturnal episodes, made it clear that waking periods of less 
than 60 min could occur within otherwise coherent sleep periods. Therefore, in the following analyses, two successive sleep episodes are considered as such when separated by at least $60 \mathrm{~min}$ of wakefulness.

Overall Characteristics of Sleep and Wakefulness during Disentrainment

Figure 1 shows the alternation of sleep and wakefulness for all subjects, after applying the criteria for sleeping and waking episodes described above. A total of 57 sleep episodes were spontaneously initiated and terminated during the period of disentrainment. This number does not include sleep episodes taken on the baseline night, nor does it include the last sleep episodes in disentrainment which were intentionally terminated to end the experiment.

The median duration of sleep episodes was $2.4 \mathrm{~h}$ (mean, $4.1 \mathrm{~h}$; SD, $3.7 \mathrm{~h}$; range, 0.52-12.8 h). As can be seen in Fig. 2 , the distribution of sleep episode durations was skewed, with $68.4 \%$ of all sleep episodes recorded continuing for less than $4 \mathrm{~h}$. Only 10 of the 57 sleep periods recorded continued for as long as $8 \mathrm{~h}$. Considering all sleep obtained during the period of disentrainment, i.e., from the awakening at 0800 following the baseline night to the termination $72 \mathrm{~h}$ later, for those eight subjects whose sleep was recorded for the entire period, an average of $31.0 \mathrm{~h}$ ( $43.1 \%$ of the period) was spent asleep (range: $20.5-40.2 \mathrm{~h}$ ). (Due to equipment failure, the EEG of one subject (GLB) was recorded for only the first $48 \mathrm{~h}$ of disentrainment.)

Waking episodes recorded during disentrainment also tended to be substantially shortened relative to normal conditions, with a median duration of $4.9 \mathrm{~h}$ (mean, $5.2 \mathrm{~h}$; SD, $3.1 \mathrm{~h}$; range, 1.0-13.0 h). On only one occasion did a subject maintain wakefulness for longer than $12 \mathrm{~h}$ ( see Fig. 2).

It is clear, then, that subjects in disentrainment typically slept for shorter durations and remained awake for shorter periods between sleep episodes than do humans under conditions of daily life. As a result, the average sleep/wake cycle length, measured from the onset of one sleep episode to the onset of the next, was $10.2 \mathrm{~h}$ (SD, $4.4 \mathrm{~h}$; median, $10.6 \mathrm{~h})$. Variability in duration of sleep/wake cycles was decreased by about $25 \%$ (to $3.4 \mathrm{~h}$ ) without substantially altering cycle length 

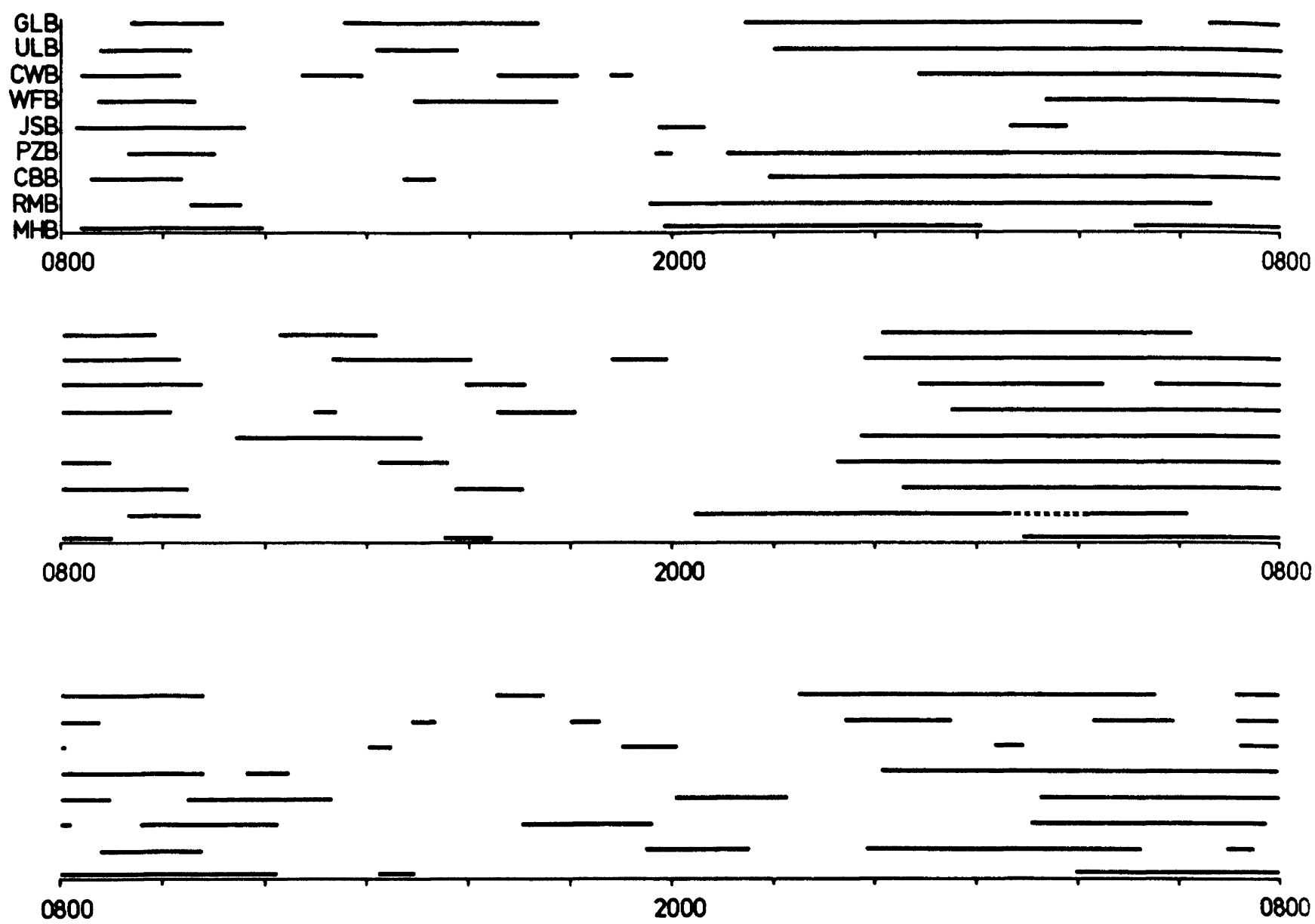

Fig. 1. Alternation of sleep (dark bars) and wakefulness for all subjects across the period of disentrainment. The EEG of one subject (GLB) was recorded for only the first $48 \mathrm{~h}$ of disentrainment. Broken line in fifth sleep episode of subject RMB indicates a loss of signal during that interval

$(9.9 \mathrm{~h})$ by calculating the cycle from the middle of one sleep episode to the middle of the next.

Temporal Characteristics

Figure 3 shows the distribution of sleep period onsets during disentrainment as a function of time of day. In order to have sufficient sample size in each cell for statistical analysis, it was necessary to group sleep onset times in $3-h$ blocks. The overall distribution did not differ significantly from a chance distribution $\left(x^{2}=8.3, d f=7\right.$, ns) nor did the number of sleep onsets between 1400 and 1700 , or between 2300 and 0200 , differ significantly from the number of sleep onsets in adjacent $3-h$ blocks. 


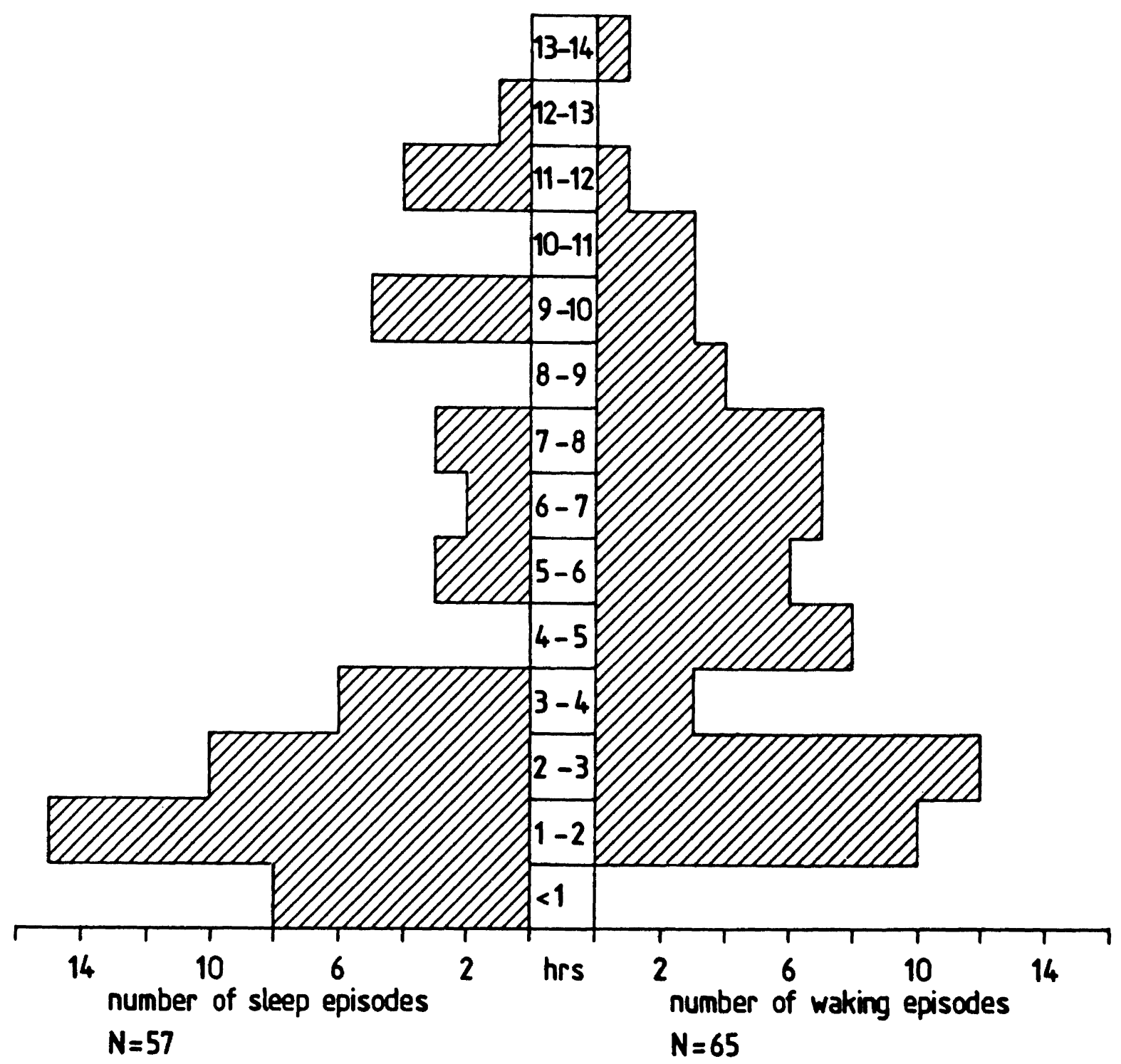

Fig. 2. Distribution of sleep and waking episodes recorded during disentrainment, as a function of their durations. Both sleep and waking episodes showed tendencies to continue for substantially shorter durations than under conditions of daily life

Since sleep onset can occur, of course, only when a subject is awake, the frequency distribution shown in Fig. 3 was influenced substantially by the circadian variation in sleep period duration. For example, the frequency of sleep onset was relatively low between 0200 and 0500 primarily because subjects had earlier initiated their major nocturnal sleep episodes. As such, sleep onset time may be a misleading index of group sleep tendency. A more meaningful representation of group sleep tendency may be derived from the examination of Fig. 4, which shows the number of sleep episodes, as a percentage of total possible sleep episodes, comprising part or all of any given hour across the nychthemeron. Placement of sleep was clearly bimodal, with 


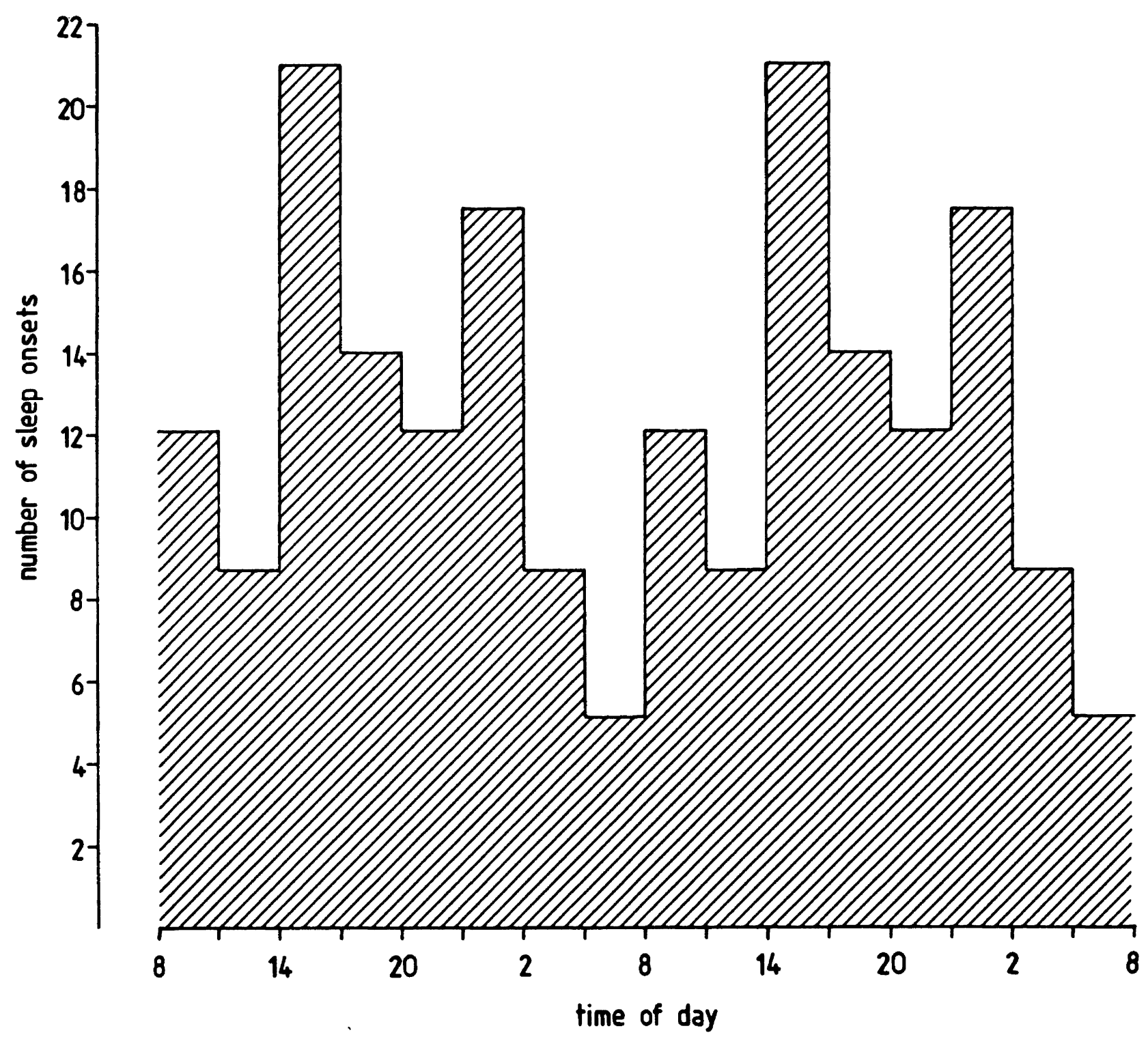

Fig. 3. Distribution of sleep period onsets recorded during disentrainment, plotted across the nychthemeron (double-plotted). For statistical analysis onsets were grouped in $3-h$ blocks. Distribution did not differ significantly from chance

a major peak between 0200 and 0600 , and a second, less robust, peak between 1400 and 1700 .

While sleep onsets occurred throughout the nychthemeron, and group tendency for sleep was clearly bimodal, the duration of sleep episodes clearly followed a circadian course, as shown in Fig. 5. Sleep episodes initiated between 0800 and 2000 continued for a median duration of $1.4 \mathrm{~h}$. On only two occasions during this interval did sleep episodes continue for longer than $3 \mathrm{~h}$. In contrast, sleep periods initiated between 2000 and 2400 continued for a median duration of $7.2 \mathrm{~h}$, with a decreasing trend in median durations over the subsequent $8 \mathrm{~h}$. 


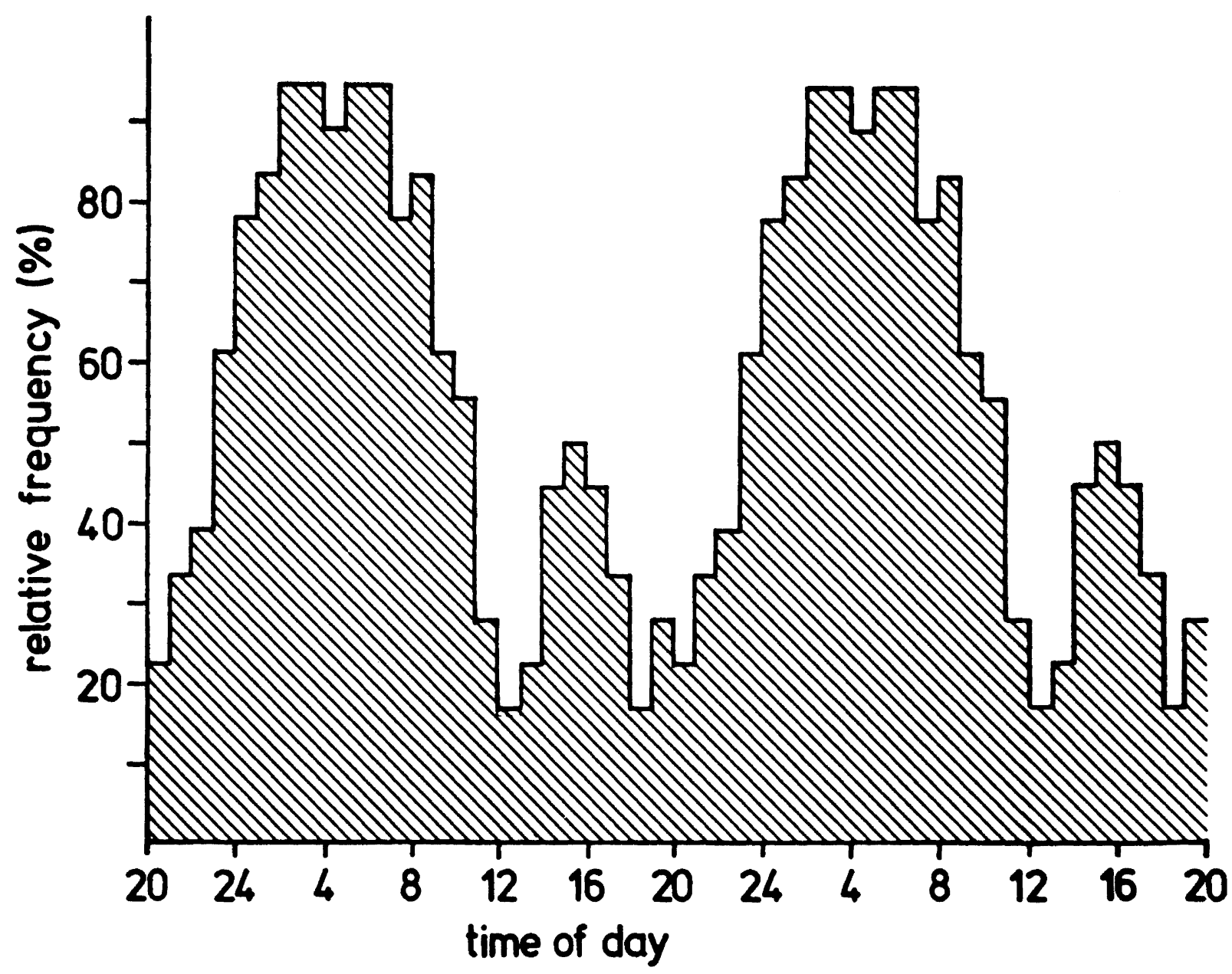

Fig. 4. Distribution of the number of sleep episodes, as a percentage of total possible sleep episodes, comprising all or part of any given hour across the nychthemeron (double-plotted)

Characteristics of Major Sleep Episodes and Naps

Results presented thus far have focused on the characteristics of sleep, in general, during disentrainment: sleep episodes have been treated as a homogeneous group. However, it is apparent from these analyses, and from inspection of Fig. 1, that two general categories of sleep episodes are distinguishable, primarily on the basis of their durations (Fig. 5) and placement within the 24-h day (Fig. 4).

Twenty-one sleep episodes (in addition to baseline sleep periods) were comparable with usual nocturnal sleep episodes in that they were of relatively long duration and were typically initiated after 2000 . These sleep periods (total $N=30$ ) have been designated major sleep episodes (MSEs) in the following analyses. Naps were operationally defined as any sleep episode occurring between two MSEs. Twenty-three sleep episodes could be designated as naps, based on this criterion. 


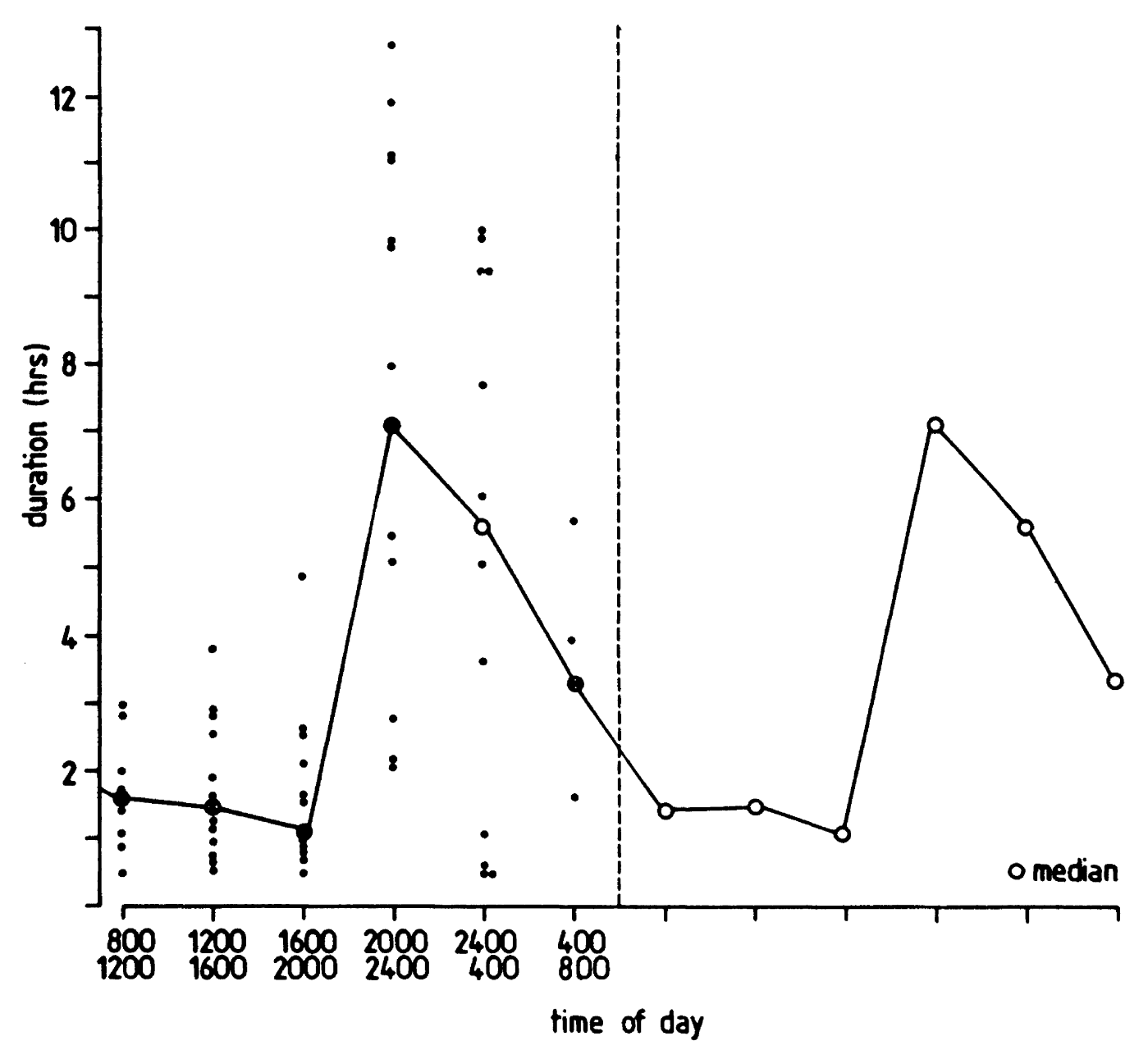

Fig. 5. Distribution of sleep episodes across the nychthemeron (in 4-h blocks, double-plotted), as a function of sleep episode duration. Each dot represents a sleep episode, baseline nights are included

Because some sleep periods resembled neither MSEs nor met the criterion for naps, they are excluded from the following analyses.

Eighteen MSES were both spontaneously initiated and spontaneously terminated. The median duration of these episodes was $9.8 \mathrm{~h}$ (mean, $8.8 \mathrm{~h}$; SD, $2.7 \mathrm{~h})$. This is compared with a median duration for naps $(N=23)$ of $1.4 \mathrm{~h}$ (mean, $1.7 \mathrm{~h} ; S D, 0.9 \mathrm{~h}$ ). The difference in durations for the two groups was significant (Mann-Whitney $U=6.5, p \leqq 0.0001$, twotailed). There was also a significant difference $(U=33, p \leqq 0.001$, two-tailed) in durations of waking episodes prior to MSEs (mean, $7.7 \mathrm{~h}$; SD, $2.6 \mathrm{~h}$; median, $7.5 \mathrm{~h}$ ) vs those preceding naps (mean, $3.6 \mathrm{~h}$; SD, $1.6 \mathrm{~h}$; median, $3.1 \mathrm{~h}$ ). 
Temporal Relations

As a first step in the analysis of temporal relationships among MSEs and naps, the relationship between successive MSEs was examined. During the first days in a time-free environment it is not uncommon for subjects to exhibit transient states in which the onsets of successive MSEs do not necessarily occur systematically later, as is typical in the "free-running" condition. As can be seen in Table 1, this was clearly the case in the $72 \mathrm{~h}$ of disentrainment. Only one subject (CBB) showed systematically later sleep onset times for MSEs. However, a clear free-running trend was present in the mean group data, with the mean "day" (measured from the onset of a MSE to the onset of the next MSE) during disentrainment continuing for $25.2 \mathrm{~h}$.

Also shown in Table 1 are onset times of successive naps across the 3 days of disentrainment. As was the case with MSEs, most subjects did not show tendencies for systematically later onset times for nap sleep (notably, the only subject who showed "free-running" in MSEs also exhibited "free-running" naps). However, also in correspondence with the findings of MSES, there was a clear trend for naps to "run free" when group data were considered. Because on a few occasions a single subject exhibited two naps on a given day, it was necessary to calculate more than one mean "nap day" (measured from the mean onset of naps on one day to the mean onset of naps on the following day). However, as can be seen, values did not differ significantly, and the mean "nap day" continued for about $24.8 \mathrm{~h}$.

In summary, then, slightly over $25 \mathrm{~h}$ separated one MSE from the next during disentrainment. Similarly, on average, slightly under $25 \mathrm{~h}$ separated successive nap episodes during the disentrained period.

Placement of Naps Relative to MSES

Our next step in temporal analysis was to examine the placement of naps relative to adjacent MSES. The average sleep/wake cycle length for all MSES and naps (i.e., from the onset of each MSE to the onset of a subsequent nap, and from the onset of each nap to the onset of the subsequent MSE) was $12.3 \mathrm{~h}$ (SD, $3.8 \mathrm{~h}$; median, $12.3 \mathrm{~h}$ ). However, there was a difference in the cycle lengths measured from MSEs to naps (mean, $14.6 \mathrm{~h} ; \mathrm{SD}, 2.8 \mathrm{~h}$ ) and those measured from nap onsets to sub- 
Table 1. Onset times for successive major sleep episodes (MSEs) and for successive naps. (Blanks do not necessarily mean subject did not sleep, but rather that sleep periods could not be classified as naps or MSES.)

\begin{tabular}{|c|c|c|c|c|c|c|c|}
\hline \multirow{2}{*}{ Subject } & \multirow{2}{*}{ Baseline } & \multicolumn{2}{|c|}{ Disentrained 1} & \multicolumn{2}{|c|}{ Disentrained 2} & \multicolumn{2}{|c|}{ Disentrained 3} \\
\hline & & $\mathrm{Nap}$ & MSE & & MSE & Nap & MSE \\
\hline GLB & $00: 40$ & $13: 32$ & $21: 24$ & $12: 15$ & $00: 09$ & - & - \\
\hline ULB & $00: 03$ & $14: 09$ & $22: 00$ & $13: 17 / 18: 48$ & $23: 46$ & $16: 31$ & $22: 26$ \\
\hline CWB & $00: 09$ & $12: 40 / 16: 31$ & $00: 50$ & $15: 56$ & $00: 50$ & $14: 52 / 17: 50$ & $23: 23$ \\
\hline WFB & $23: 57$ & $14: 55$ & $03: 19$ & $16: 52$ & $01: 26$ & $18: 59$ & - \\
\hline JSB & $23: 29$ & $\longrightarrow$ & - & - & $23: 43$ & - & $00: 06$ \\
\hline PZB & $23: 22$ & - & $21: 04$ & $14: 12$ & $23: 14$ & $\longrightarrow$ & - \\
\hline CBB & $01: 07$ & $14: 41$ & $21: 55$ & $15: 42$ & $00: 32$ & $17: 01$ & $03: 04$ \\
\hline RMB & $23: 06$ & $10: 30$ & $19: 49$ & $9: 17$ & $20: 24$ & $8: 47$ & $\longrightarrow$ \\
\hline MHB & $02: 36$ & - & - & $15: 28$ & $02: 54$ & $14: 14$ & $03: 57$ \\
\hline \multicolumn{8}{|l|}{ MSE } \\
\hline $\begin{array}{l}\text { Mean } \\
(S D)\end{array}$ & $\begin{array}{c}24: 17 \\
(1.1 \mathrm{~h})\end{array}$ & & $\begin{array}{l}22: 37- \\
(2.6 \mathrm{~h})\end{array}$ & $25.5 \mathrm{hk}$ & $\begin{array}{l}-24: 07 \\
(1.8 \mathrm{~h})\end{array}$ & $=24.9 \mathrm{~h}$ & $\begin{array}{r}-24: 59 \\
(2.4 \mathrm{~h})\end{array}$ \\
\hline $\begin{array}{l}\text { Nap } \\
\text { Mean } \\
(\text { SD) }\end{array}$ & $\begin{array}{r}1 \\
(1 .\end{array}$ & $\begin{array}{l}: 25 / 14: 03 \\
\text { h) }(2.0 \mathrm{~h})\end{array}$ & & $\begin{array}{l}14: 07 / 14: 49 \\
2.5 \mathrm{~h})(2.9 \mathrm{~h})\end{array}$ & 0 & $\begin{array}{l}15: 04 / 15: 34 \\
3.5 \mathrm{~h})(3.7 \mathrm{~h})\end{array}$ & \\
\hline
\end{tabular}


sequent MSES (mean, $9.9 \mathrm{~h} ; \mathrm{SD}, 3.3 \mathrm{~h}) \quad(U=76, \mathrm{p} \leqq 0.0001$, twotailed). In other words, the initiation of naps tended to occur about $60 \%$ through the MSE to MSE sleep/wake cycle.

Relationships to Temperature

As previously noted, group data revealed free-running trends for successive onsets of both MSEs and of naps, as well as circasemidian periodicity between MSEs and subsequent naps. We next analyzed the relationship between the circadian rhythm of body core temperature and the two groups of sleep episodes, as shown in Fig. 6 . The figure shows the average temperature curve for all subjects across the $72 \mathrm{~h}$ of disentrainment and the baseline night. Above the temperature curve is a summation histogram showing the number of subjects asleep during all or part of any given hour during disentrainment. Shown below the temperature curve (black bars) are the average onsets and durations of MSEs and naps, as described in Table 1.

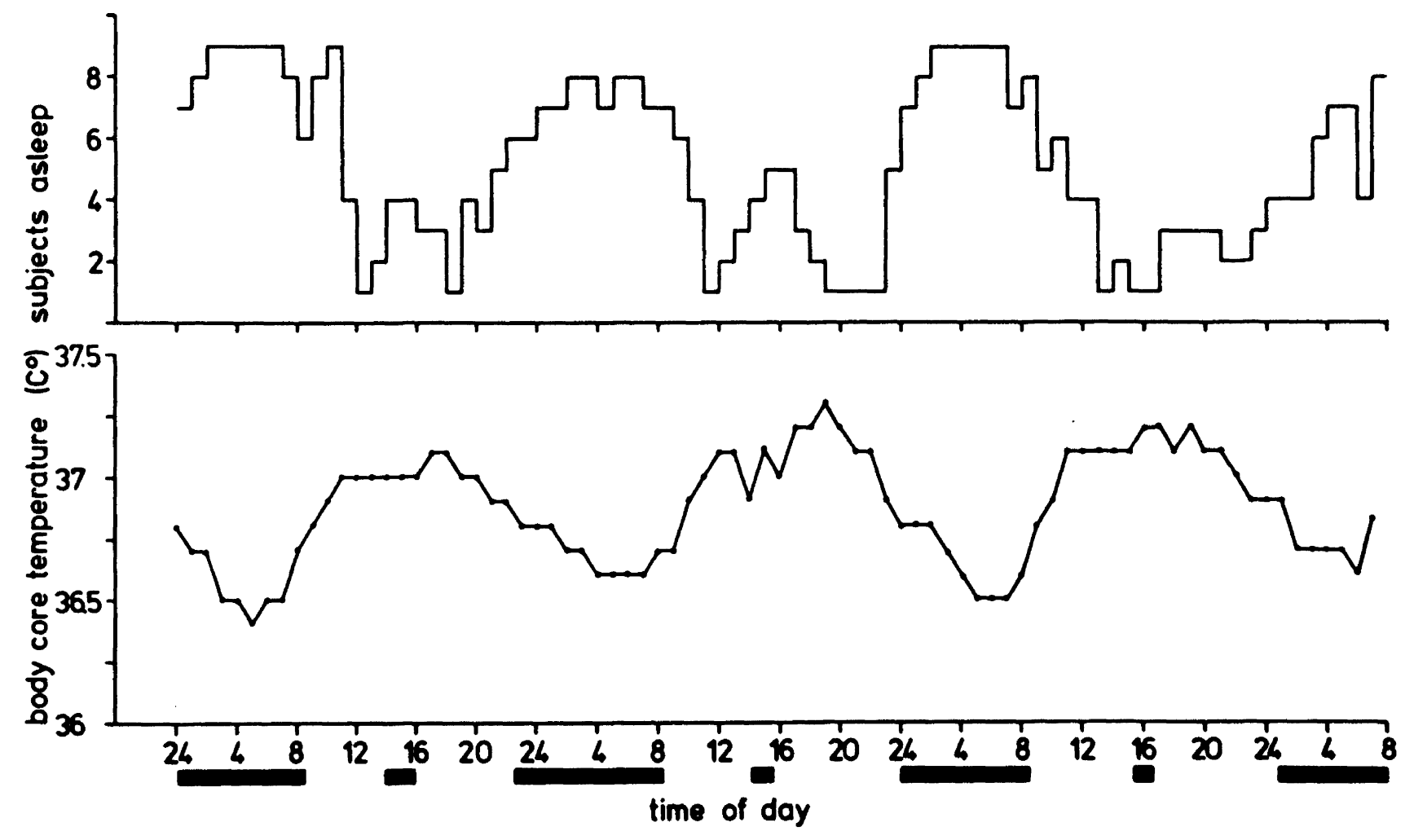

Fig. 6. Relationship between sleep episodes recorded in disentrainment and circadian rhythm of body core temperature. Above the temperature curve (averaged across all subjects) is a summation histogram of the number of subjects asleep during any given hour during disentrainment. Shown below the temperature curve (black bars) are average onsets and durations of major sleep episodes and naps 
Group sleep tendency, both for MSEs and naps, exhibited a clear phase relationship with body core temperature. As in all free-running conditions, the MSEs (as reflected by average onset time as well as total number of subjects sleeping) corresponded to the troughs in temperature. Indeed, this circadian sleep tendency was essentially a mirror image of the circadian rhythm in body core temperature. In addition, there were clear tendencies for average nap times to occur in correspondence with daily maxima in temperature. This tendency is best seen in the middle of the figure (day 2 of disentrainment) when group sleep tendency was robust enough to result in a transient drop in average temperature.

\section{Structural Characteristics}

A final analysis concerned the comparison of structural parameters of MSEs vs naps. Overall structural parameters of the two groups of sleep episodes are shown in Table 2. Only REM sleep percentages differed significantly between the two groups, with naps averaging about $30 \%$ lesS REM sleep than MSEs. However, the variability of mean percentages associated with naps were typically about twice that of corresponding values for MSEs. Such variability is particularly evident with regard to stage 4 values, where the difference between mean and median measures is dramatic $(7.8 \%$ vs $0.61 \%)$. The distribution of stage 4 values during naps was essentially bimodal with naps being characterized by either no stage 4 or over $10 \%$ of stage 4 . Naps with onsets between 1300 and 1700 showed median stage 4 amounts of $5.5 \%$. In contrast, all other naps were characterized by median stage 4 values of $0 \%$. In general, then, naps occurring toward the middle of the nap distribution showed a greater tendency for the occurrence of stage 4 .

\section{DISCUSSION}

Given conditions under which little was allowed to obstruct the unambiguous expression of a putative ultradian propensity for sleep, i.e., sleep itself, subjects exhibited sleep/wake behavior characterized by a clearly bimodal, albeit broad, distribution in the occurrence of sleep. Thus, the present examination of sleep patterns recorded under conditions of disentrainment obtained results which are consistent with, and lend considerable support to, the notion that the human 
Table 2. Overall structural parameters of major sleep episodes (MSES) and naps recorded during disentrainment

\begin{tabular}{lccccc}
\hline & \multicolumn{2}{c}{ Major sleep episodes } & \multicolumn{3}{c}{ Naps } \\
\cline { 2 - 5 } Latency & Mean (SD) & Median & Mean (SD) & Median \\
\hline SWS & 14.3 min $(4.5)$ & 14.5 & 19.1 min (9.4) & 19.0 \\
REM & 91.3 min $(44.9)$ & 75.5 & $48.4 \min (14.2)$ & 49.3
\end{tabular}

Stage $(\%)$

\begin{tabular}{|c|c|c|c|c|c|c|}
\hline 0 & 5.5 & $(3.4)$ & 5.5 & 5.6 & $(6.7)$ & 2.9 \\
\hline 1 & 4.6 & $(2.2)$ & 4.4 & 6.6 & $(6.5)$ & 5.5 \\
\hline 2 & 55.1 & $(6.3)$ & 53.9 & 58.5 & $(12.2)$ & 58.0 \\
\hline 3 & 7.6 & $(3.9)$ & 7.2 & 7.5 & $(8.4)$ & 4.3 \\
\hline 4 & 7.3 & $(3.6)$ & 6.9 & 7.8 & $(11.3)$ & 0.6 \\
\hline$R$ & 19.8 & $(7.1)$ & 20.5 & 13.7 & $(10.3)$ & 15.5 \\
\hline$\underset{(\%)}{\operatorname{Comp} l e t e}$ & & 100 & & & 60.9 & \\
\hline $\begin{array}{c}\text { Usual } \\
\text { sleep stage } \\
\text { sequencing } \\
(\%)\end{array}$ & & 100 & & & 100 & \\
\hline $\begin{array}{c}\text { Sleep } \\
\text { duration }\end{array}$ & $8.8 \mathrm{~h}$ & $(2.7)$ & 9.8 & $1.7 \mathrm{~h}$ & $(0.89)$ & 1.4 \\
\hline $\begin{array}{c}\text { Prior } \\
\text { wakefulnes }\end{array}$ & $s^{7.7 h}$ & $(2.6)$ & 7.5 & $3.6 \mathrm{~h}$ & $(1.6)$ & 3.1 \\
\hline
\end{tabular}

sleep/wake system is characterized not only by a strong propensity to obtain a MSE once per circadian day, but also by a prominent tendency for a shorter sleep episode to occur roughly halfway between successive "night's sleep" episodes.

The finding that average nap times maintained a general phase relationship not only with MSES, but also with the group average rhythm of body core temperature, suggests that the organization of naps within the nychthemeron was a consequence of the existence of a second preferred phase position for sleep, located around the temperature maximum. This suggestion is also supported by a recent study in which we analyzed the data of subjects who, contrary to experimental instructions, napped during isolation under typical time-free conditions 
(ZULLEY and CAMPBELL 1985a,b). Sleep episodes subjectively perceived as "naps", and with durations similar to those of naps in the present study, showed a clear tendency to occur about halfway between successive minima of body core temperature.

Under entrained conditions, such a phase position for sleep tendency would correspond to the early afternoon (roughly 1400-1600), a time when the vast majority of napping occurs in populations in which napping is frequently reported (DINGES et al. 1983; OGUNREMI 1978; OKUDAIRA et al. 1983; WEBB 1978). This interval also corresponds to a time of peak occurrence of stage 2 in the EEGs of young adults attempting to sleep every $20 \mathrm{~min}$ across the day (LAVIE and SCHERSON $1981)$.

The relationship between naps and the phase of body core temperature was also reflected in predictable alterations in structural features of these sleep episodes, relative to MSES. REM sleep amounts show clear circadian variations, with minimum percentages typically recorded during sleep episodes occurring in coincidence with maximum body core temperature (AKERSTEDT and GILLBERG 1981; ENDO et al. 1981; HUME and MILLS 1977). This circadian variation in REM sleep amount resulted in the only significant difference in sleep stage percentages between major and nap sleep episodes.

Likewise, the well-established circadian variation in REM sleep latency (CAMPBELL and ZULLEY, in press; HUME 1978; KARACAN et al. 1970; TAUB and BERGER 1973; WEBB and AGNEW 1978) resulted in significant differences between the two groups of sleep episodes in that measure as well (see Table 2).

These structural differences notwithstanding, and despite the extreme differences in average duration of naps vS MSEs (also as a result of the influence of the circadian rhythm of body core temperature; CZEISLER et al. 1980; ZULLEY 1980), the two groups of sleep periods showed remarkable similarities in overall structure and makeup. Probably as a consequence of their abbreviated durations, about one-third of the naps were characterized by the absence of slow-wave sleep (SWS), REM sleep, or both states of sleep. However, all "complete" naps (i.e., those containing both SWS and REMS) showed sleep stage sequencing characteristic of typical (nocturnal) sleep, with SwS preceding the first epoch of REM sleep at sleep onset. Furthermore, there were no significant differences in the sleep stage percentages 
between complete naps and MSEs. Thus, in contrast to the findings of WEITZMAN et al. (1974) regarding scheduled naps, our findings indicate that naps, taken ad libitum, quite often are miniatures of the normal $8 \mathrm{~h}$ sleep pattern. From these findings it can be concluded that the same general rules governing structural aspects of MSEs also hold for the composition of naps.

Both the finding that naps maintain a general phase relationship with body core temperature, and that they share structural similarities with MSES, militate against the interpretation that the relatively brief sleep episodes observed in the disentrained environment were taken simply in response to boredom. Rather, the findings indicate that naps are regulated by the same mechanism(s) mediating nocturnal sleep, and occur as a manifestation of an underlying, periodically recurring propensity for sleep.

Additional support for this position is provided by studies of napping behavior in environments which are not characterized by such drastic minimization of behavioral alternatives to sleep. Simple instructions to "sleep when you feel sleepy", given to a subject in an otherwise normal time-free environment, resulted in a doubling of the number of sleep episodes which occurred during an interval of equal duration (10 days) during which the subject was instructed not to nap (CAMPBELL and ZULLEY in preparation). WEBB and AGNEW (1974) reported similar findings in seven subjects maintained under equivalent conditions. And, as mentioned above, instructions not to nap do not guarantee that napping will not occur. Such examples seem to confirm the ubiquity of napping behavior, provided that sufficient release from experimental or social constraints on such behavior is a feature of the environment.

Nevertheless, it is quite likely that the basal, static behavioral conditions of disentrainment contributed to an increase in the likelihood that the physiological tendency for sleep would be expressed unambiguously in the form of naps. This, of course, was the rationale behind invoking such conditions.

An additional result of the elimination of controls on sleep initiation and the minimization of behavioral options to sleep was to increase the average proportion of the nychthemeron spent asleep. Subjects averaged $10.4 \mathrm{~h}$ of sleep per $24 \mathrm{~h}$ in disentrainment compared with the 7-8 h typical of normal conditions. The increase was due both 
to a Iengthening of MSEs as well as the addition of nap sleep. At least a portion of this increase in total sleep time is probably due to the conditions imposed.

The sleep recorded from human subjects under these conditions is comparable with the sleep recorded from other animals under standard laboratory conditions. It is generally accepted that under such conditions, in which nutritional requirements are met, no restrictions are placed on sleep, and the recording chamber is generally devoid of behavioral alternatives to sleep (despite the opportunity for free movement in the chamber), the amounts of sleep observed reflect the system working at maximum capacity rather than at a level which, in daily life, is limited by environmental demands such as predator pressure, or, in the case of humans, social and occupational pressures.

Whether such limitations on the sleep system result in chronic sleep deprivation is a matter of conjecture. WEBB and AGNEW (1975) have presented considerable data to suggest that if we are not, in fact, chronically sleep deprived, we are, minimally, on inveterate "sleep diets". (Kleitman (1963, p. 307) cites a source (Camp 1923) who "maintained that many people sleep too long and that oversleeping is just as reprehensible as overeating".)

Whether we are deprived or simply restrained by our environment, it is clear that the exclusion of naps from our usual sleep orgnization can be tolerated indefinitely (virtually an entire lifetime) without noticeably detrimental consequences. However, that we are able to function reasonably well without them should not diminish the relevance of naps in the understanding of the nature and the functions of sleep. In the introduction of this chapter, we drew a parallel between the human sleep system, as it functions under the influence of behavior controls, and a river, the course of which has been modified by the imposition of artificial barriers. As with the human system, the milieu of the river is essentially undamaged by the establishment of such controls, and its utility to society is clearly enhanced as a consequence of such structuring. As such, the imposition of behavioral controls is beneficial.

Yet, if one wishes to examine the natural history of the river, barriers such as dams and levees lose their utility and instead become impediments, probably contributing to spurious, or, at best, incomplete conclusions regarding the river's true course and characteris- 
tics. In the same way, the natural progression of sleep and wakefulness across the nychthemeron cannot be adequately evaluated in the presence of restrictions on the system which have the potential to influence its true expression.

In summary, the present findings indicate that when the obstructions are removed, what remains is a rather labile organization of sleep and wakefulness characterized by at least two intervals of elevated drowsiness per circadian day, tied to the temperature cycle, and distinguished by their differential strengths. It is the presence and relative strength of environmental restraints that determines the extent to which these noncircadian variations in sleep propensity will be expressed in the unequivocal form of naps.

\section{REFERENCES}

AKERSTEDT T, GILLBERG M (1981) The circadian variation of experimentally displaced sleep. Sleep 4(2):159-169

BENOIT 0 (1984) Homeostatic and adaptive roles of human sleep. Experientia $40: 437-440$

BROUGHTON RJ (1975) Biorhythmic variations in consciousness and psychological functions. Can Psychol Rev 16(4):217-239

CAMPBELL SS (1984) Duration and placement of sleep in a "disentrained" environment. Psychophysiology 21(1):106-113

CAMPBELL SS, ZULLEY J (in press) Rhythmic components of sleep structure during disentrainment

CZEISLER CA, WEITZMAN ED, MOORE-EDE MC, ZIMMERMAN JC, KNAUER RS (1980) Human sleep: its duration and organization depend on its circadian phase. Science 210:1264-1267

DINGES DF, ORNE EC, ORNE MT (1983) Napping in North America: a siesta rhythm? Symposium abstracts, 4 th International congress of sleep research, p 86

ENDO $S$, KOBAYASHI T, YAMAMOTO T, FUKUDA H, SASAKI M, OHTA T (1981) Persistence of the circadian rhythms of REM sleep: a variety of experimental manipulations of the sleep-wake cycle. Sleep $4(3): 319-328$

HUME KI (1978) Some electrophysiological studies of sleep from subjects on varying sleep-wakefulness schedules. Thesis, University of Manchester

HUME KI, MILLS JN (1977) Rhythms of REM and slow-wave sleep in subjects living on abnormal time schedules. Waking Sleeping 1:291-296

KARACAN I, FINLEY WW, WILLIAMS RL, HURSCH CJ (1970) Changes in stage 1-REM and stage 4 sleep during naps. Biol Psychiatry 2:261-265 
KLEITMAN N (1963) Sleep and wakefulness. University of Chicago Press, Chicago

LAVIE P, SCHERSON A (1981) Ultrashort sleep-waking schedule. I. Evidence of ultradian rhythmicity in "sleepability". EEG Clin Neurophysiol 52:163-174

NAKAGAWA Y (1980) Continuous observation of EEG patterns at $n$ ight and in daytime of normal subjects under restrained conditions. I. Quiescent state when lying down. EEG Clin Neurophysiol 49:524-537

OGUNREMI 0 (1978) The subjective sleep pattern in Nigeria. Sleep Res $7: 163$

OKUDAIRA $N$, FUKUDA H, OHTANI K, NISHIHARA K, ENDO S, TORII S (1983) Napping patterns in the elderly in Vilcabamba, Ecuador. Symposium abstracts, 4 th International congress of sleep research, $p 88$

RECHTSCHAFFEN A, KALES A (eds) (1968) A manual of standardized terminology, techniques and scoring system for sleep stages of human subjects. U.S. Department of Health, Education and Welfare, NIH, Washington

TAUB J, BERGER R (1973) Sleep stage patterns associated with acute shifts in the sleep-wakefulness cycle. EEG Clin Neurophysiol 35:613619

TUNE $G$ (1968) Sleep and wakefulness in normal human adults. Br Med J $2: 269-271$

TUNE G (1969) Sleep and wakefulness in 509 normal human adults. Br J Med Psychol 42:75-80

WEBB WB (1978) Sleep and naps. Speculations in Sci Technol 1:313-318

WEBB WB, AGNEW HW (1974) sleep and waking in a time-free environment. Aerospace Med 45:617-622

WEBB WB, AGNEW HW (1975) Are we chronically sleep deprived? Bull Psychonomic SOC 6:47-48

WEBB WB, AGNEW HW (1978) Effects of rapidly rotating shifts on sleep patterns and sleep structure. Aviat Space Environ Med 49(2):384-389

WEBB WB, DUBE MG (1981) Temporal characteristics of sleep. In: ASCHOFF $\mathrm{J}$ (ed) Handbook of behavioural neurobiology, vol 4. Biological rhythms. Plenum, New York, pp 499-522

WEITZMAN ED, NOGEIRE C, PERLOW M, FUKUSHIMA D, SASSIN J, MCGREGOR P, GALLAGHER TF, HELLMANN L (1974) Effects of a prolonged 3-hour sleepwake cycle on sleep stages, plasma cortisol, growth hormone and body temperature in man. J Clin Endocrinol 38(6):1018-1029

WEVER RA (1979) The circadian system of man. Springer, Berlin Heidelberg New York

WHITE R (1974) Sleep length and variability: measurement and interrelationships. Dissertation, University of Florida

ZULLEY J (1980) Distribution of REM sleep in entrained 24-hour and free-running sleep-wake cycles. Sleep 2(4):377-389 
ZULLEY J, CAMPBELL SS (1985a) The coupling of sleep-wake patterns with the rhythm of body temperature. In: KOELLA W, RÜTHER E, SCHULZ H (eds) Sleep 1984: proceedings of the 7 th European congress of sleep research. Fischer, stuttgart (in press)

ZULLEY J, CAMPBELL SS (1985b) Napping behavior during "spontaneous internal desynchronization": sleep remains in synchrony with body temperature. Hum Neurobiol (in press) 